\title{
Location of injected polymethylmethacrylate microspheres influences the onset of late adverse effects: an experimental and histopathologic study
}

This article was published in the following Dove Press journal:

Clinical, Cosmetic and Investigational Dermatology

6 August 2015

Number of times this article has been viewed

Luciano Henrique de Jesus

Laura de Campos

Hildebrand

Manoela Domingues

Martins

Francinne Miranda da Rosa

Chris Krebs Danilevicz

Manoel Sant'Ana Filho

Department of Oral Pathology, School of Dentistry, Universidade Federal do Rio Grande do Sul, Porto Alegre, RS, Brazil

Correspondence: Luciano Henrique de Jesus

School of Dentistry, Universidade Federal do Rio Grande do Sul, Rua Ramiro

Barcelos 2492, Porto Alegre,

RS, 90035-003, Brazil

Tel +55513308501 I

Fax +55 5I 33085005

Email drlhjesus@gmail.com

\begin{abstract}
Polymethylmethacrylate (PMMA) has been widely used in the correction of wrinkles because of its long-lasting cosmetic improvements. However, side effects and complications may occur, and its clinical appearance on the oral mucosa can be similar to that of inflammatory or neoplastic disease. The aim of this research was to compare the clinical and histopathologic responses to PMMA injected by two different methods. Twenty-two rats received an injection of PMMA using the tunneling technique (gold standard), with subcutaneous deposition of the filler in the face, or a variation of the technique with transcutaneous submucosal deposition of the filler in the cheek. The tissue reaction was analyzed clinically every 24 hours during the first week, then once a week for the following 3 months. Histologic evaluation was based on the local inflammatory response to the filler. No clinical changes were observed during the initial evaluation period (0-14 days). After 14 days, only the submucosal group showed extra-oral enlargement $(n=4,18.2 \%)$. Histopathologic analysis revealed nodule formation in four animals $(18.2 \%)$ in the submucosal group, with no nodules observed in the subcutaneous group. The data obtained in this study demonstrate that the technique used to deliver the filler may influence the risk of adverse reactions.
\end{abstract}

Keywords: dermal filler, polymethylmethacrylate, adverse reactions

\section{Introduction}

Injectable filler substances are important cornerstones of modern esthetic surgery and are often used in the treatment of wrinkles, acne scars, and facial lipodystrophy. The apparent simplicity of the filler injection procedures and the relatively high patient satisfaction rates have led to an increase in the use of these treatments. ${ }^{1-8}$

The filling materials can be classified as non-biodegradable or biodegradable according to their interaction with the body. Non-absorbable or permanent fillers are stable throughout an individual's life time, but biodegradable or transient fillers are absorbed by the body after months or even years. ${ }^{1,3-5}$ They are further differentiated as volumetric, structural, or fibroplastic according to the biomechanics of filling. The ideal injectable material should offer good esthetic results and have a long-lasting effect. In addition, it should be safe, biocompatible, and stable at the implant site, with minimal complications and no risk of migration. Unfortunately, the ideal filler has yet to be discovered, and all currently used fillers may induce adverse reactions. ${ }^{1,2,5}$

The benefits and efficacy of each filler material, along with their side effects and complications, are related to product composition, impurities, or injection method. ${ }^{4,5,9-11}$ Complications can be classified as early (0-14 days), late (14 days to 1 year), or delayed $\left(>1\right.$ year). ${ }^{6}$ They may occur as nodular masses in the perioral region, ${ }^{2,3,5,8,11-13}$ 
resembling inflammatory or neoplastic disease, especially of the salivary glands. Late and delayed complications often appear as nodules, granulomas, or chronic suppurative infection that may result from an immune response to the product or biofilm-infected granulomas. ${ }^{14}$ The treatment for such side effects can be intralesional injection of corticosteroids or antimitotic and systemic steroids. Surgical removal is contraindicated on the face because it may leave scars, but nodules in the lips can be excised, with the best approach from the inside. ${ }^{8,15}$

Polymethylmethacrylate (PMMA)-based fillers are biphasic, permanent, and composed of PMMA microspheres suspended in a vehicle solution of bovine collagen or methylcellulose. They are widely used for permanent correction of prominent nasolabial folds, marionette lines, and deep glabellar furrows. ${ }^{2,4,7,12,16,17}$ There is a wide array of PMMA-based injectable products available which have been approved, including PMMA in collagen (Artefill ${ }^{\circledR}$, Suneva Medical Inc., San Diego, CA, USA), PMMA in carboxyglutamate (Metacrill ${ }^{\circledR}$, Nutricel, Rio de Janeiro, RJ, Brazil), and PMMA in carboxymethylcellulose (Newplastic ${ }^{\circledR}$, Lebon Produtos Químicos e Farmacêuticos, Porto Alegre, RS, Brazil). Other hydroxyethylmethacrylate particles suspended in hyaluronic acid (DermaLive ${ }^{\circledR}$, Dermatech, Paris, France) and polyvinyl hydroxide microspheres suspended in polyacrylamide gel (Evolution ${ }^{\circledR}$, ProCytech SA, Bordeaux, France), have been withdrawn from the market. ${ }^{18-23}$

With the increasing use of PMMA fillers, it is likely that the prevalence of PMMA-related complications will increase. Artecoll ${ }^{\circledR}$ (Hafod Bioscience BV, Nijmegen, The Netherlands) and Artefill are the most commonly studied PMMA-containing formulations and have been used extensively throughout the world. Artefill is a third-generation
PMMA-based filler product, which is an improved version of its predecessor (Artecoll), and its safety and efficacy have been demonstrated in well-controlled multicenter trials. ${ }^{2,20}$ Reports on the biocompatibility and safety of other PMMA-containing formulations, however, are still scarce in the literature. The biocompatibility and safety of PMMA are related to its highly uniform, round, and smooth-surfaced microspheres, and in particular to the absence of particles less than $20 \mu \mathrm{m}$ in diameter. ${ }^{4,17,19,20,24,25}$

The normal host response to cosmetic filler is a weak foreign body reaction. ${ }^{2}$ However, PMMA implants have the potential to elicit a cellular immune response in humans, although the mechanism of this late inflammation or granuloma formation is still unknown. ${ }^{5,8,18,25}$ We hypothesized that one of the variables involved in modulation of the tissue response to dermal fillers is the injection site. With this in mind, we compared the clinical and histopathologic response to PMMA injected at two different sites, ie, subcutaneously and submucosally.

\section{Materials and methods}

Twenty-two 12-month-old, female Wistar rats were used in this study. The animals were maintained under controlled laboratory conditions $\left(22^{\circ} \mathrm{C}\right.$ room temperature, $40 \%$ relative humidity, and a 12-hour light/dark cycle). The animals were fed on solid chow and water ad libitum before and throughout the experimental period.

The animals were anesthetized intramuscularly with $1 \mathrm{~mL} / \mathrm{kg}$ of $1 \%$ ketamine $\mathrm{HCl}$ (Dopalen, Vetbrands, São Paulo, SP Brazil) and 2\% xylazine (Anasedan, Vetbrands, São Paulo, SP Brazil). All animals then received a $0.1 \mathrm{~mL}$ injection of PMMA (10\% Newplastic; Lebon Produtos Químicos e Farmacêuticos) with a $26 \mathrm{G}$ needle $(0.45 \mathrm{~mm})$ subcutaneously or submucosally.
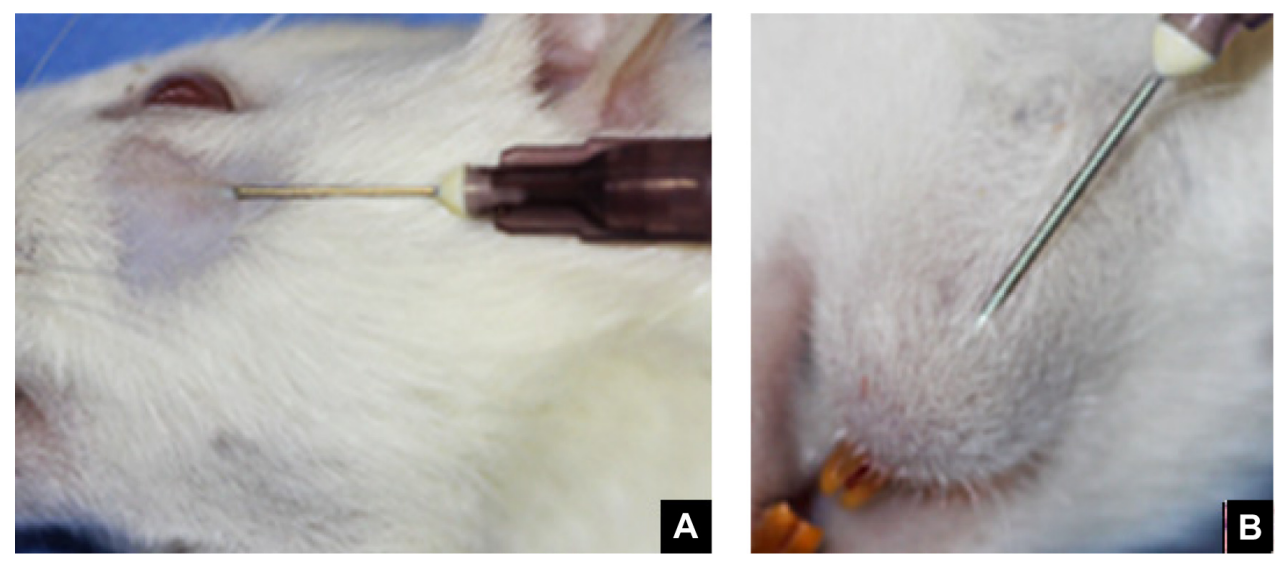

Figure I Techniques for subcutaneous and submucosal PMMA injection.

Notes: (A) Technique for subcutaneous injection: PMMA was injected in the infraorbital region. The needle was introduced subcutaneously using the tunneling technique. (B) Technique for submucosal injection: PMMA was injected submucosally via extra-oral access. The needle was introduced through the skin, crossed the muscle fibers, and the material was deposited in the submucosal tissue.

Abbreviation: PMMA, polymethylmethacrylate. 
PMMA was injected subcutaneously in the infraorbital region using the tunneling technique, as described elsewhere in the literature ${ }^{17}$ (Figure 1A), or submucosally under the inferior labial mucosa via extra-oral access (Figure 1B). Using the latter technique, the needle was introduced through the skin, across the muscle fibers, and the material was deposited in the submucosal tissue of the lip. The animals were euthanized with an overdose of anesthesia 3 months after the dermal filler injections. The areas where PMMA had been injected were excised, fixed in $10 \%$ buffered formalin for 24 hours, embedded in paraffin, sectioned by microtome ( $3 \mu \mathrm{m}$ per section), and stained with hematoxylin-eosin.

\section{Clinical evaluation}

The tissue reaction was analyzed clinically every 24 hours during the first week, then once a week for the following 3 months. Any visible changes, such as extra-oral enlargement, drainage of pus, or changes in animal behavior and/or weight that could indicate the presence of clinical symptoms were evaluated. A semiquantitative analysis was performed as follows: an absence of clinical changes was assigned a score of 0 and the presence of clinical changes, a score of 1 . At the end of the experiment, the results of clinical evaluation were classified as early changes (0-14 days) or late changes (14 days to 3 months). ${ }^{6}$

\section{Histologic evaluation}

Histologic evaluation was based on the local inflammatory response to the dermal filler. The criteria used to classify the inflammatory response were developed based on a article by Duranti et al ${ }^{26}$ (Table 1).

A semiquantitative analysis was performed by two previously calibrated but non-biased examiners (LCH and FMR) using a conventional light microscope. Calibration training preceded the experimental analyses and was conducted under the supervision of an experienced pathologist. Intra-examiner calibration was achieved by repeating the analysis of one in

Table I Grading scale for inflammatory response

\begin{tabular}{ll}
\hline Grade & Histopathologic aspects \\
\hline 0 & Lack of material \\
1 & $\leq 10 \%$ inflammatory cells and formation of \\
& connective tissue septa within PMMA spheres \\
$10 \%-50 \%$ inflammatory cells and formation \\
of collagen fibers within PMMA spheres \\
$\geq 50 \%$ inflammatory cells and formation of \\
\\
3 & collagen fibers within PMMA spheres \\
& Granulation tissue with foreign-body reaction \\
& or encapsulation of PMMA spheres
\end{tabular}

Note: Data from Duranti et al. ${ }^{2}$

Abbreviation: PMMA, polymethylmethacrylate. every ten samples and applying the kappa coefficient $(k>0.7)$ to determine the degree of agreement. The examiners were unaware of the experimental group to which each sample belonged.

\section{Ethical approval}

This study was approved by the institutional review board of the Universidade Federal do Rio Grande do Sul and by the research ethics committee of the School of Dentistry, Universidade Federal do Rio Grande do Sul, Porto Alegre, RS, Brazil (protocol 17794/2010). The study was designed and conducted in compliance with ethical standards of animal use in research projects, as described in Normative Resolution 04/97 of the Institutional research ethics committee (Group for Research and Graduate Studies/Hospital de Clínicas de Porto Alegre, RS, Brazil). ${ }^{27}$

\section{Statistical analysis}

The data were analyzed using the Kruskal-Wallis exact test, the permutation method for the adjusted P-values for multiphase comparisons, and Fisher-Freeman-Halton exact test followed by multiple comparisons via permutation tests. Permutation tests were based on 20,000 replicates. All $P$-values presented are the bilateral type and values less than 0.05 were considered statistically significant. Statistical analysis was performed using SAS version 9.2 (Statistical Analysis System, Cary, NC, USA).

\section{Results}

\section{Clinical evaluation}

The clinical evaluation results are shown in Table 2. No clinical changes were observed during the initial evaluation period (0-14 days). After 14 days (late changes), only the submucosal group showed extra-oral enlargement $(n=4,18.2 \%)$.

\section{Histologic evaluation}

The inflammatory response in the subcutaneous and submucosal groups 3 months after PMMA injection are shown in Table 3. In the subcutaneous group, 17 animals (77.3\%) had a grade 1 inflammatory response and five $(22.7 \%)$ had grade 2 (Figure 2). None of the animals showed grade 0,3 , or 4 inflammatory responses. In the submucosal group, nine animals $(41.0 \%)$ showed a grade 1 inflammatory response and eight animals (36.3\%) had a grade 2 response. Granulation tissue with total encapsulation of the PMMA implant (grade 4) was observed in the samples from four rats (18.2\%, Figures $3 \mathrm{~A}$ and $3 \mathrm{~B}$, and 4$)$. The animals with a local histopathologic reaction (grade 4) were the same ones that showed extra-oral enlargement on clinical evaluation. There were significant differences in 
Table 2 Clinical evaluation of local inflammatory response according to PMMA injection site $(n=22)$

\begin{tabular}{lllllll}
\hline Anatomic site & Clinical score & & $\begin{array}{l}\text { Extra-oral } \\
\text { enlargement (n) }\end{array}$ & $\begin{array}{l}\text { Pus } \\
\text { drainage (n) }\end{array}$ & $\begin{array}{l}\text { Weight } \\
\text { loss (n) }\end{array}$ & $\begin{array}{l}\text { Behavior } \\
\text { change (n) }\end{array}$ \\
\hline Subcutaneous & Early (0-14 days) & Absent & 22 & 22 & 22 & 22 \\
& Early (0-14 days) & Present & 0 & 0 & 0 & 0 \\
& Late (3 months) & Absent & 22 & 22 & 22 & 22 \\
Submucosal & Late (3 months) & Present & 0 & 0 & 0 & 0 \\
& Early (0-14 days) & Absent & 22 & 0 & 22 & 0 \\
& Early (0-14 days) & Present & 0 & 22 & 22 & 0 \\
& Late (3 months) & Absent & 18 & 0 & 0 & 22 \\
\hline
\end{tabular}

Abbreviation: PMMA, polymethylmethacrylate.

the comparative histopathologic analysis between injection sites (Table 4).

\section{Discussion}

The ideal material for treatment of wrinkles or soft tissue augmentation should offer good esthetic results with a long-lasting effect. It should also be safe, biocompatible, and stable at the implantation site, with minimal complications and no risk of migration. ${ }^{1,2,4,5,14}$ Although this esthetic treatment is considered relatively safe, the use of injectable dermal fillers is a minimally invasive treatment, and as with any medical procedure, there is a risk of unwanted side effects. ${ }^{4}$ These complications can be related to the injection site, such as nodule formation in the lips, resembling inflammatory or neoplastic disease. Our study revealed a significant difference in the comparative histopathologic analysis between subcutaneous and submucosal injection sites. Only the submucosal site was associated with total implant encapsulation 3 months after injection of the dermal filler.

When a filler is injected, some tissue reactions may occur as a result of the product composition, even if the procedure is performed correctly, whereas some reactions may arise as

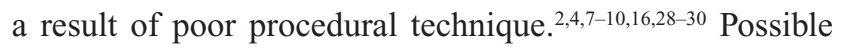
failures resulting from PMMA injection may be due to errors in the injection application method used, such as needle size, uneven distribution, inadequate volume, and depth of placement of the material. . $4,5,10,16,18,24-26,29$ The best results for PMMA application are expected to be achieved by injecting the material into the subdermal layer of the skin. ${ }^{5,17}$
In this study, the same type and amount of PMMA were injected in both experimental groups, and only the application technique was different for the two groups. Most cases treated with the technique recommended in the literature (ie, tunneling), ${ }^{17}$ in which the material is injected subcutaneously, showed formation of connective tissue septa within PMMA spheres and minimal inflammatory infiltrate, indicating that the material was stable at the injection site. However, in the group treated with the modified PMMA application technique, the material crossed the dermis and muscle layers and was deposited in the submucosa, with increased formation of nodular lesions at the injection site and encapsulation of the material as evidenced by histologic examination (18.4\%).

According to the literature, the pattern of tissue response associated with implantation of PMMA in humans corresponds to an initial foreign body reaction., ${ }^{2,14,12,24,28,30} \mathrm{After}$ a 3-month period, all PMMA microspheres are expected to be completely surrounded by fibroblasts and collagen fibers. ${ }^{2}$ This was observed in our subcutaneous injection group. However, the submucosal group showed a more marked adverse reaction, especially encapsulation of the total implant and formation of a nodule. This result may be explained by the depth of penetration of the injection and muscle movements around the filler. ${ }^{4,10,29}$ If the filler is deposited too deeply or too superficially, the result is a whitish nodule with undesirable cosmetic effects. ${ }^{2,5,10,29}$ Granulomas usually appear in 6-24 months, but may arise many years after injection. ${ }^{1-3,5,10,12,14,16}$ In this study, no granulomatous reaction was observed, but tissue reactions were analyzed for only 3 months after filler injection.

Table 3 Histopathologic evaluation of local inflammatory response according to PMMA injection site

\begin{tabular}{|c|c|c|c|c|c|c|}
\hline \multirow{2}{*}{$\begin{array}{l}\text { Anatomic } \\
\text { site }\end{array}$} & \multicolumn{6}{|c|}{ Inflammatory response } \\
\hline & Grade 0 & Grade I & Grade 2 & Grade 3 & Grade 4 & Total \\
\hline Subcutaneous (n) & 0 & 17 & 5 & 0 & 0 & 22 \\
\hline Submucosal (n) & I & 9 & 8 & 0 & 4 & 22 \\
\hline
\end{tabular}

Abbreviation: PMMA, polymethylmethacrylate. 


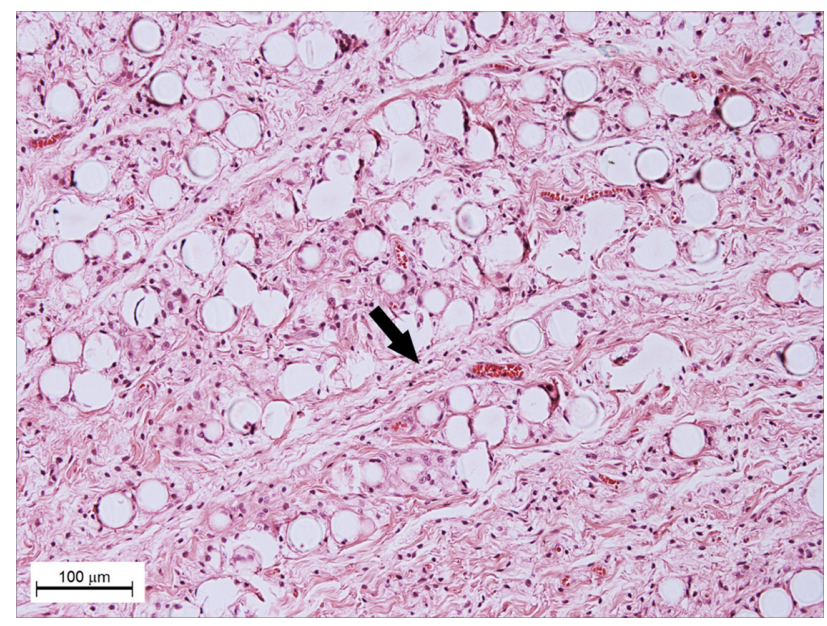

Figure 2 Microscopic appearance after 3 months: few inflammatory cells and formation of connective tissue septa within PMMA spheres.

Notes: Microscopic appearance 3 months after PMMA injection in the subcutaneous group showing few inflammatory cells and formation of connective tissue septa (black arrow) within PMMA spheres characterizing degree I of inflammation (hematoxylineosin, 200× magnification).

Abbreviation: PMMA, polymethylmethacrylate.

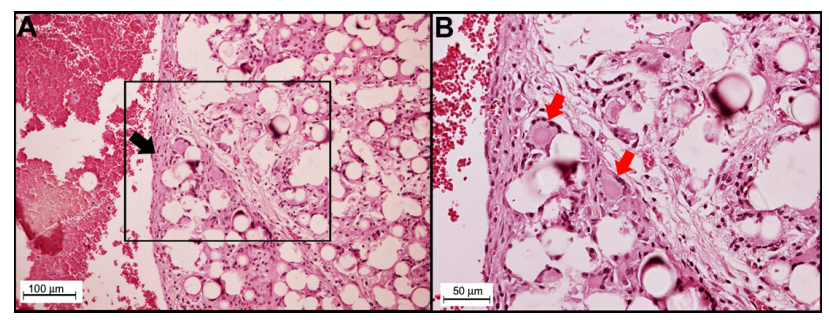

Figure 3 Microscopic appearance 3 months after PMMA injection in the submucosal group.

Notes: (A) Nodule formation with a capsule of connective tissue and mononuclear inflammatory infiltrate (black arrow) involving PMMA microspheres, characterizing degree 4 of inflammation (hematoxylin-eosin, 200× magnification). (B) Greater detail of the region demarcated by the square in the image $(\mathbf{A})$ showing the presence of multinucleated giant cells (red arrows) on the surface of PMMA microspheres (hematoxylin-eosin, 400× magnification).

Abbreviation: PMMA, polymethylmethacrylate.

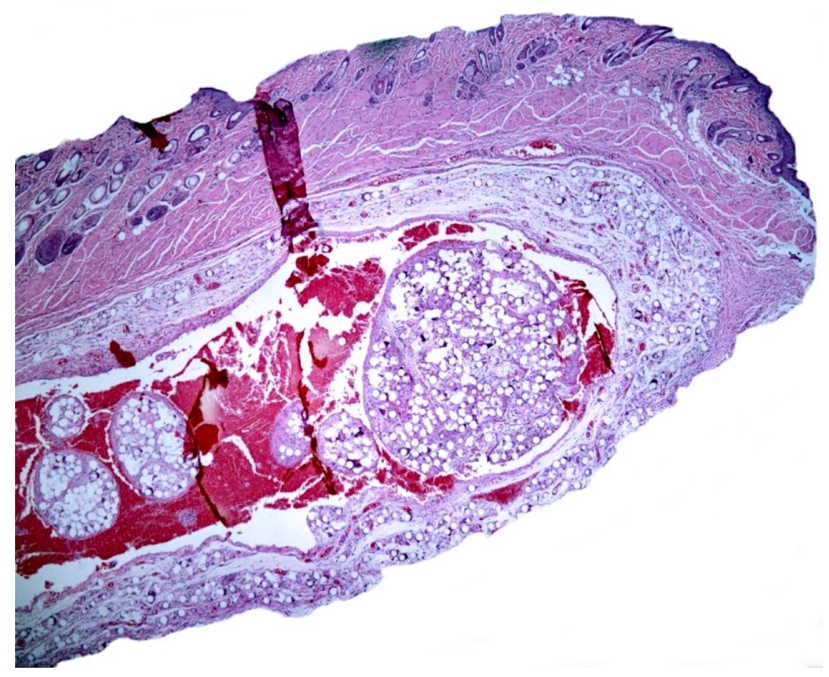

Figure 4 Microscopic appearance of PMMA injection in submucosal group 3 months after PMMA injection, (hematoxylin-eosin, in minor magnification).

Abbreviation: PMMA, polymethylmethacrylate.
Table 4 Comparative analysis of local inflammatory response to PMMA according to injection site

\begin{tabular}{lllll}
\hline Anatomic site & $\mathbf{n}$ & Mean & SD & P-value \\
\hline Subcutaneous & 22 & 1.23 & 0.43 & 0.0009 \\
Submucosal & 22 & 1.86 & 1.17 & 0.0009 \\
\hline
\end{tabular}

Note: Multiple comparisons of proportions using permutation resampling method $(P<0.05)$.

Abbreviations: PMMA, polymethylmethacrylate; SD, standard deviation.

According to Lemperle et al, ${ }^{21}$ all fillers are at risk of being overinjected, remodeled, or dislocated when deposited into or close to a facial muscle. The muscle movement may form a nodule or "grain", which may be more evident in the lips and corners of the mouth. This type of nodule formation can be due to inadequate implantation technique and should not be confused with real foreign body granulomas. Nodules occur quite often when a physician is learning how to inject the filler by a new technique or using a new implant. ${ }^{21,29}$ This highlights the importance of training in all injection techniques before applying them to patients. Nodules are isolated single lumps in the implanted area with a fibrous capsule that shields them from the surrounding tissue. Macroscopically, they are white and harder than a genuine granuloma, because they contain fewer cellular elements, and are palpable or visually evident a few weeks after injection..$^{21}$ These clinical and histopathologic features were observed in the present study, specifically in the submucosal group.

The PMMA filler used in this study was $10 \%$ Newplastic. In a study by Piacquadio et al, ${ }^{23}$ this product was associated with wide variability in particle size $(0.2-70 \mathrm{~mm})$, morphology (nonspherical and conjoined spheres), and presence of small impurities when compared with other brands available on the market. Uniform size, shape, and smooth surface of PMMA microspheres, combined with the correct injection technique, are important for obtaining a well-controlled inflammatory reaction, with adequate volume of material for cosmetic purposes. ${ }^{2,4,5,7,10,17,19,20,24}$ The authors have related the onset of adverse reactions in response to the type of PMMA used in this study to its lower degree of purity, because this filler is composed of particles that are smaller than the ideal size, which facilitates activation of macrophages and the cellular immune system, as well as the possibility of late granulomas. ${ }^{19}$ However, in the present study, we used the same product in all animals, while changing only the injection site, and found that use of a different technique was sufficient to produce adverse effects. Further studies investigating the effects of the injection technique using other commercially available brands of PMMA-containing formulations are needed. 
In conclusion, the technique used for injection of a PMMA filler plays a key role in the onset of adverse reactions, and incorrect application of the material may lead to nodule formation and undesired clinical results.

\section{Acknowledgments}

The authors are grateful to the staff of the histopathology laboratory, JJ Barbachan, School of Dentistry-Universidade Federal do Rio Grande do Sul, Brazil, and the Coordenação de Aperfeiçoamento de Pessoal de Nível Superior (for a PhD scholarship).

\section{Disclosure}

The authors report no conflicts of interest in this work.

\section{References}

1. Carruthers J, Cohen SR, Joseph JH, Narins RS, Rubin M. The science and art of dermal fillers for soft-tissue augmentation. J Drugs Dermatol. 2009;8:335-350.

2. Gilbert E, Hui A, Meehan S, Waldorf HA. The basic science of dermal fillers: past and present Part II: adverse effects. J Drugs Dermatol. 2012;11:1069-1077.

3. Lombardi T, Samson J, Plantier F, et al. Orofacial granulomas after injection of cosmetic fillers. Histopathologic and clinical study of 11 cases. J Oral Pathol Med. 2004;33:115-120.

4. Luebberding S, Alexiades-Armenakas M. Safety of dermal fillers. J Drugs Dermatol. 2012;11:1053-1058.

5. Requena C, Izquierdo MJ, Navarro M, et al. Adverse reactions to injectable aesthetic microimplants. Am J Dermatopathol. 2001;23:197-202.

6. Sclafani AP, Fagien S. Treatment of injectable soft tissue filler complications. Dermatol Surg. 2009;35:S1672-S1680.

7. Serra MS, Oyafuso LK, Trope BM, Munhoz Leite OH, Ramos-e-Silva M. An index for staging facial lipoatrophy and evaluation of the efficacy of the treatment with polymethylmethacrylate in HIV/AIDS patients: a pilot study. J Eur Acad Dermatol Venerol. 2013;27:990-996.

8. Sturm LP, Cooter RD, Mutimer KL, Graham JC, Maddern GJ. A systematic review of dermal fillers for age-related lines and wrinkles. $A N Z$ J Surg. 2011;81:9-17.

9. Lemperle G, Gauthier-Hazan N, Wolters M, Eisemann-Klein M, Zimmermann U, Duffy DM. Foreign body granulomas after all injectable dermal fillers: part 1. Possible causes. Plast Reconstr Surg. 2009; 123:1842-1863.

10. Park TH, Seo SW, Kim JK. Clinical experience with polymethylmethacrylate microsphere filler complications. Aesthetic Plast Surg. 2012;36:421-426

11. Vargas KF, Borghetti RL, Moure SP, Salum FG, Cherubini K, de Figueiredo MA. Use of polymethylmethacrylate as permanent filling agent in the jaw, mouth and face regions - implications for dental practice. Gerodontology. 2011;29:e16-e22.
12. Medeiros CC, Cherubini K, Salum FG, de Figueiredo MA. Complications after polymethylmethacrylate (PMMA) injections in the face: a literature review. Gerodontology. 2014;31: 245-250.

13. Mercer SE, Kleinerman R, Goldenberg G, Emanuel PO. Histopathologic identification of dermal filler agents. J Drugs Dermatol. 2005;9:1072-1078.

14. Carpaneda EM, Carpaneda CA. Adverse results with PMMA fillers. Aesthetic Plast Surg. 2012;36:955-963.

15. Christensen L. Normal and pathologic reactions to soft tissue gel fillers. Dermatol Surg. 2007;33:5168-5172.

16. Lemperle G, Gauthier-Hazan N. Foreing body granulomas after all injectable dermal fillers: part 2. Treatment options. Plast Reconstr Surg. 2009;123:1864-1873.

17. Lemperle G, Gauthier-Hazan N, Lemperle M. PMMA-microspheres (Artecoll) for long-lasting correction of wrinkles: refinements and statistical results. Aesthetic Plast Surg. 1998;22:356-365.

18. Lemperle G, Knapp TR, Sadick NS, Lemperle SM. ArteFill permanent injectable for soft tissue augmentation: I. Mechanism of action and injection techniques. Aesthetic Plast Surg. 2012;34:264-272.

19. Costa IMC, Salaro CP, Costa MC. Polymethylmethacrylate facial implant: a successful personal experience in Brazil for more than 9 years. Dermatol Surg. 2009;35:1221-1227.

20. Lemperle G, Romano JJ, Busso M. Soft tissue augmentation with Artecoll: 10-years history, indications, techniques and complications. Dermatol Surg. 2003;29:573-587.

21. Lemperle G, Sadick NS, Knapp TR, Lemperle SM. ArteFill permanent injectable for soft tissue augmentation: II. Indications and applications. Aesthetic Plast Surg. 2010;34:273-286.

22. Narins RS, Bowman PH. Injectable skin fillers. Clin Plast Surg. 2005;32:151-162.

23. Piacquadio D, Smith S, Anderson R. A comparison of commercially available polymethylmethacrylate-based soft tissue fillers. Dermatol Surg. 2008;34:S48-S52.

24. Lemperle G, De Fazio S, Nicolau P. Artefill: a third generation permanent dermal filler and tissue stimulator. Clin Plast Surg. 2006;33: 551-565.

25. Lemperle G, Morhenn VB, Pestonjamasp V, Gallo RL. Migration studies and histology of injectable microspheres of different sizes in mice. Plast Reconstr Surg. 2004;113:1380-1390.

26. Duranti F, Salti G, Bovani B, Calandra M, Rosati ML. Injectable hyaluronic acid gel for soft tissue augmentation. A clinical and histological study. Dermatol Surg. 1998;24:1317-1325.

27. Goldim JR, Raymundo MM. Ética aplicada à Pesquisa em Animais [Ethics applied to research in animals]; 2008. Available from: http:// www.bioetica.ufrgs.br/textos.htm\#animal. Accessed January 23, 2015. Portuguese.

28. Moure SP, de Vargas KF, Borghetti RL, et al. Clinical and pathological characteristics of polymethylmethacrylate and hyaluronic acid in the rat tongue. Int J Oral Maxillofac Surg. 2012;41:1296-1303.

29. DeLorenzi C. Complications of injectable fillers, Part I. Aesth Surg J. 2013;33:561-575.

30. Medeiros CC, Borghetti RL, Nicoletti N, da Silva VD, Cherubini K, Salum FG, de Figueiredo MA. Polymethylmethacrylate dermal fillers: evaluation of the systemic toxicity in rats. Int J Oral Maxillofac Surg. 2014;43:62-67.
Clinical, Cosmetic and Investigational Dermatology

\section{Publish your work in this journal}

Clinical, Cosmetic and Investigational Dermatology is an international, peer-reviewed, open access, online journal that focuses on the latest clinical and experimental research in all aspects of skin disease and cosmetic interventions. All areas of dermatology will be covered; contributions will be welcomed from all clinicians and

\section{Dovepress}

basic science researchers globally. This journal is indexed on CAS The manuscript management system is completely online and includes a very quick and fair peer-review system, which is all easy to use. Visit http://www.dovepress.com/testimonials.php to read real quotes from published authors 